\title{
Mammographic evaluation of palpable breast masses with pathological correlation: a tertiary care centre study in Nepal
}

\author{
G. Gurung, R. K. Ghimire, B. Lohani \\ Department of Radiology and Imaging, Tribhuvan University Teaching Hospital \\ Correspondence to: Ghanshyam Gurung, Department of Radiology and Imaging \\ Tribhuvan University Teaching Hospital, Kathmandu, Nepal \\ Email: puspaghan@mos.com.np
}

\begin{abstract}
Introduction: Breast cancer is one of the major health problem for all countries. . In Nepal, breast cancer is the second most common cancer in female. Early detecting tools like mammography can able to detect location, size, morphology, and nature of breast lesions that can help to reduced mortality and morbidity from breast cancer significantly.

Methods: This prospective study was carried out at the department of Radiology, Surgery and Pathology for a period of one year. A total of 100 patients with clinically palpable breast lump were subjected to mammography and subsequently to FNA or biopsy. The mammograms were reviewed by two senior consultant radiologists and pathology by a senior pathologist.

Results: Out of 100 patients, $65 \%$ had mammographic features of benign lesion and $35 \%$ had features of malignancy. Pathology revealed $64 \%$ of lesion to be benign and $36 \%$ of lesion to be malignant. There were four false negative $(6.2 \%)$ and three false positive $(8.6 \%)$ cases. The sensitivity and specificity of mammography were $88.9 \%$ and $95.53 \%$ respectively. The mean age of patient with malignant lesion was 46.3 years $(\mathrm{SD}=11.5)$ and 34.7 years $(\mathrm{SD}=10.6)$ for benign lesions. Among malignant lesion $37.1 \%$ had lobulated, $14.3 \%$ had oval, $31.4 \%$ round and $17.1 \%$ had irregular shape with spiculated margin in $60 \%$ and indistinct margins in 34.3\%. Among benign $7.7 \%$ showed lobulated shape, $41.5 \%$ oval and $50.8 \%$ round shape. Circumscribed margin was found in $93.9 \%$ of benign and $5.7 \%$ of malignant lesions.

Punctuate and polymorphic calcification was found in malignant lesions (25.7\% and 5.7\%). Secondary changes were found in only in the malignant cases. Halo sign was found only in benign cases and most common in fibroadenoma (38.4\%).

Conclusions: Mammography is an effective diagnostic tool for benign and malignant characteristic of palpable breast mass.
\end{abstract}

Keywords: Breast lump, mammography, micro calcification

\section{Introduction}

Breast cancer is one of the major health problems for developed as well as developing countries. Breast cancer occurs in approximately 6 percent of the American female and accounts for approximately 30,000 deaths annually in the United States. ${ }^{1}$ in Nepal, among cancer cases in females, frequency of breast cancer is 16.9 percent and it is second most common cancer in females. ${ }^{2}$ Mammography, is capable of revealing the location, size, morphology and in the majority of cases the nature of breast lesions. The absolute mortality rate has been significantly reduced because of efficiency of mammographic screening and its ability to find out carcinoma in situ, small infiltrating cancers at earlier 
stage. Thus, complete understanding of breast morphology and mastery of the diagnosis of breast disease and progressive steps towards expanding the use of mammography can help to reduce the breast cancer mortality and morbidity.

\section{Methods}

This Prospective study was carried out at the Department of Radiology, Surgery and Pathology. The study included 100 patients with clinically palpable breast lump. An informed and written consent was obtained from the patient for this study. Mammography was performed in craniocaudal and mediolateral projection in the dedicated mammographic unit (Lorad) with automatic exposure timings with 26-30kv. Mammograms interpretation was done by two senior consultant radiologists with consensus reading. Radiologically, the abnormalities were categorized into major and minor groups for the malignant and benign lesions. The characteristics in major groups for malignant lesion included shape, margin and calcification. Lobular and irregular shape, speculated and indistinct margins and punctuate and polymorphic calcifications were the features of malignant lesions. Benign lesions had oval and round shape with circumscribed margins and spherical calcification. The characteristics in minor groups for the malignant lesion included architectural distortion, nipple retraction, skin thickness and benign lesion has perilesional halo. Pathological sample were obtained by image guided fine needle aspiration and true cut biopsy and were reviewed by a senior pathologist. Correlation was made between mammographic and cyto/histologic diagnosis. Statistical Analysis was performed using standard statistical program (spss 10.0).

\section{Results}

100 patients with clinically palpable breast mass underwent mammography and subsequent pathological examination. Comparison of mammographic and pathologic diagnosis given in Table 1. Among them, 65\% had mammographic features of benign and 35\% had features of malignancy. Pathological examination revealed $64 \%$ of the lesion to be benign and $36 \%$ of the lesion to be malignant. Both mammographic and pathologic diagnosis was concordant in $61(61 \%)$ benign and 32(32\%) malignant cases. Among 7 discrepant lesions, 4 were mammographically benign and subsequent pathology revealed malignancy. 3 mammographically malignant lesions were benign on pathological examination. The youngest patient diagnosed as malignancy on mammography was 25 years old, with negative histopathology. The youngest patient with breast cancer both mammographically and pathologically was 32 year old.

Table 1: Comparison of mammographic and pathologic diagnosis

\begin{tabular}{|c|c|c|c|}
\hline \multirow{2}{*}{$\begin{array}{l}\text { Mammographic } \\
\text { diagnosis }\end{array}$} & \multicolumn{3}{|c|}{ FNAC/Histopathological diagnosis } \\
\hline & Benign (\%) & Malignant (\%) & Total \\
\hline Benign & $61(93.8)$ & $4(6.2)$ & 65 \\
\hline Malignant & $3(8.6)$ & $32(91.4)$ & 35 \\
\hline Total & 64 & 36 & 100 \\
\hline
\end{tabular}

Age distribution in benign and malignant lesion of breast masses is presented in Fig. 1.

The mean age of patients with malignant lesion was 46.3 years $(\mathrm{SD}=11.5)$ and maximum number of malignant cases were found in the two age groups 40-44 and 50-54. No malignant cases were found below 25 years of age. The mean age of patients with benign lesion was 34.7 years $(\mathrm{SD}=10.6)$ and maximum number of benign cases were found in 35-44 years age group.

Characteristics of major mammographic findings in benign

Fig. 1: Age distribution of patients with breast masses

and malignant masses are given in table no 2 . Among benign lesions, $50.8 \%$ had round, $41.5 \%$ had oval, and $7.7 \%$ had lobulated shape. Among malignant, 37.1\% had lobular, 14.3\% had oval, $31.4 \%$ had round and $17.1 \%$ had irregular shape. (P-value $<0.000027$ ) 
Mammographic evaluation of palpable breast masses with pathological correlation

Table 2: Mammographic findings of benign and malignant breast lesions

\begin{tabular}{lllll} 
& & Benign (65) & Malignant (35) & Total (100) \\
Shape & Lobular & $5(7.7 \%)$ & $13(37.1 \%)$ & $18(18 \%)$ \\
& Oval & $27(41.7 \%)$ & $5(14.3 \%)$ & $32(32 \%)$ \\
\multirow{3}{*}{ Margins } & Round & $33(50.8 \%)$ & $11(31.4 \%)$ & $44(44 \%)$ \\
& Irregular & $0(0 \%)$ & $6(17.4 \%)$ & $6(6 \%)$ \\
& Spiculated & $0(0 \%)$ & $21(60 \%)$ & $21(21 \%)$ \\
CalcificationTypes & Circumscribed & $61(93.9 \%)$ & $2(5.7 \%)$ & $63(63 \%)$ \\
& Indistinct & $4(6.2 \%)$ & $12(34.3 \%)$ & $16(16 \%)$ \\
& Punctate & $0(0 \%)$ & $9(25.7 \%)$ & $9(9 \%)$ \\
& Polymorphic & $0(0 \%)$ & $2(5.7 \%)$ & $2(2 \%)$ \\
& Spherical & $2(3 \%)$ & $0(0 \%)$ & $2(\%)$
\end{tabular}

In malignant lesions, spiculated margins were found in $60 \%$, indistinct margin in 34.3\% and well circumscribed margin was $5.7 \%$ cases. $93.9 \%$ benign lesion had circumscribed, and $6.2 \%$ had indistinct margin. ( $\mathrm{p}$ value $<0.000027$ )

The most common mammographic finding in malignancy was microcalcification with or without associated mass... ${ }^{3}$ In our study $25.7 \%$ malignant lesions had punctate calcification and $5.7 \%$ had polymorphic calcification whereas only $3 \%$ benign cases showed Spherical calcification.

Mammographic findings of secondary changes are given in Table 3.

Changes like architectural distortion, nipple retraction and increased skin thickness were found only in malignant cases.

Halo sign was found only in benign cases, most commonly in fibroadenoma (38.4\%)

Table 3: Mammographic findings of secondary changes in malignant breast masses

$\begin{array}{ll}\text { Malignant cases } & \\ \text { 1. With secondary changes } & \text { No. (\%) } \\ \text { (a) Nipple retraction } & 12(34.9) \\ \text { (b) Increased Skin thickness } & 11(31.4) \\ \text { (c) Architectural distortion } & 4(11.4) \\ \text { 2. Without secondary changes } & 8(22.9) \\ \text { Total } & \mathbf{3 5}(\mathbf{1 0 0})\end{array}$

Pathological findings of benign and malignant breast masses (Table 4).

Among pathologically proven benign lesion $28.1 \%$ were fibroadenoma, 33.3\% fibrocystic disease, $10.3 \%$ galactocele and $7.7 \%$ were fibroadenosis. Among malignant lesions, infiltrating ductal carcinoma was seen in $91.7 \%$, Medullary in $5.5 \%$ and mucinous carcinoma in $2.8 \%$ of cases.
Table 4: Pathological findings of benign and malignant breast masses and halo sign

$\begin{array}{llll} & \text { Types } & \text { No. (\%) } & \text { Halo sign } \\ \text { Benign (64) } & \text { Fibroadenoma } & 18(28.1) & 15(38.4) \\ & \text { Fibrocystic disease } & 23(35.9) & 13(33.3) \\ & \text { Abscess } & 4(6.2) & 0(0) \\ & \text { Simple cyst } & 9(14.1) & 4(10.3) \\ & \text { Galactocele } & 5(7.8) & 4(10.3) \\ & \text { Fibroadenosis } & 4(6.2) & 3(7.7) \\ \text { Benign phyllodes } & 1(1.6) & 0(0) \\ \text { Malignant (36) } & \text { Infiltrating ductal } & & \\ & \text { carcinoma } & 33(91.7) & 0(0) \\ & \text { Medullary } & 2(5.5) & 0(0) \\ & \text { Mucinous carcinoma } & 1(2.8) & 0(0)\end{array}$

\section{Discussion}

In the present study, the sensitivity of mammography was $88.89 \%$ and specificity $95.53 \%$. This is close to the findings shown by other authors.

In 1929 , Warren ${ }^{14}$ was able to show an $85 \%$ to $95 \%$ diagnostic accuracy of mammography where as Baker ${ }^{15}$ found $88 \%$, Mc. Clow ${ }^{16} 87 \%$, Strax ${ }^{18} 67 \%$ and Lesnick ${ }^{17}$ showed only $42 \%$ of sensitivity of mammography.

In our study, the mean age of the malignant lesion was 46.3 years and maximum number of malignancy was found in the two age groups 40-44 and 50-54. No malignant lesions were found below 25 years of age. The mean age of the benign lesion was 34.7 years and maximum numbers of benign cases were found in 35-44 years.(p value 0.000001)

Seidman $\mathrm{H}$, et.al. found less than $3 \%$ of malignancy in patients below 35 years and less than $1 \%$ below 30 years. ${ }^{4}$ In India J.E. Park found mean age of malignancy was 42 years. ${ }^{2}$ Budhathoki TB, et al found 3.7\% malignancy in 40 48 years. ${ }^{5}$ The series of Sayami and Nakarmi et al, ${ }^{6}$ showed the mean age of malignancy was 51 years. Our findings are similar to these authors. 
In the present study, maximum malignant lesion showed lobulated shape (37.1\%) and spiculated margin (60\%). Circumscribed margin was found in only two cases $(5.7 \%)$ of medullary carcinoma. Maximum numbers of benign lesions showed round $(50.8 \%)$ or oval $(41.5 \%)$ shape with circumscribed $(93.9 \%)$ margin. Similar morphology was found in the series of Mclelland with typical benign mass round or oval shaped with smooth contours and majority of these lesions were cysts or fibroadenomas. ${ }^{7}$

Meyer J.E. et. al., reported 5\% of malignancy with circumscribed mass appearing benign. Medullary, papillary, mucinous and metastatic carcinoma and some ductal carcinoma might show circumscribed mass in mammogram. ${ }^{8,9}$ Hence at times mammography could be misleading in malignant lesions.

We found microcalcifications in $31.4 \%$ of malignant lesion and punctuate $(25.7 \%)$ type was the most common. Microcalcification was not found in the benign lesion.

The study in screening mammography by Ellen, et al showed the most common mammographic finding of malignancy as microcalcification with or without associated masses $(38 \%){ }^{3}$

Powell, et al, found microcalcifications in approximately $40 \%$ of all breast cancer, either as an isolated sign or in combination with other abnormal radiographic findings, such as mass, architectural distortion or asymmetry. ${ }^{10}$ Millis found microcalcification on mammography at least in 30\% of malignancy and $70 \%$ in histology. ${ }^{11}$

In our study, secondary breast changes (nipple retraction $43.3 \%$ and skin thickness $31.4 \%$ architectural distortion $11.4 \%$ ) were found only in the malignancy and halo sign was found only in the benign lesions, most commonly in fibroadenoma.

Yorkshire breast cancer group found nipple retraction in 43 (4\%) of 1205 patients with operable breast cancer. ${ }^{12}$ Tomm E, et al identified partial radiolucent halos in $32(73 \%)$ lesions, 38 (86\%)were cysts; 3 (7\%) fibroadenomas; 2 (4\%) infiltrating ductal carcinomas; and $1(2 \%)$ axillary lymph node metastasis in total 44 masses. ${ }^{13}$

\section{Conclusions}

Mammography is an effective diagnostic tool capable of revealing the location, size and morphology of the breast lesions. Certain morphological features are very characteristic for benign and malignant lesion with fallacies in very minority of cases. Hence it has a unique role in the diagnosis of breast lesion with high sensitive and specificity.

\section{References}

1. Enid F, Gilbert B. Pathology of the breast. Breast Imaging; 1989. p. 5.

2. Park JE. Epidemiology of chronic non-communicable disease and conditions. Text book of preventive and social medicine. 12th ed. 1989. p. 245.

3. Ellen S, Luisa P, Marsteller and Bernand V, Edan. Breast cancers in women 35 years of age and younger: Mammographic, pathologic correlation. Radiology 1990; $77: 117-9$

4. Seidman H, Mushinski MH. Breast cancer: incidence, mortality, survival, and prognosis. Journal of the American College of Surgeons 1994;178(4):390.

5. Budhathoki TB, Ghimire RK, Shrestha A. Mammography in TUTH, Souvenir. 1998. p. 6.

6. Nakarmi KK, Sayami P, Shrestha BMS, Koirala B. Pattern of breast cancer at TUTH, Souvenir, IV International Surgical Conference of Society of Surgeons of Nepal, 26-28 March 1998;7.

7. Mcllelland R. Stellate lesions of the breast. In: Moskowifz M, editor. Diagnosis categorical course in breast imaging. Oak Book III: Radiology society of North America; 1986. p. 27-30.

8. Meyer JE, Amin E, Lindfors KK, Lipman JC, Stomper PC, Genest D. Medullary carcinoma of the breast:Mammographic and US appearancel Radiology 1989;170:79-82.

9. Schneider JA. Invasive papillary breast carcinoma:Mammographic and sonographic appearance. Radiology 1989;171:377-9.

10. Powell RW, Mc. Sweeney MB, Wilson CE. X-ray calcification as the only basis for breast biopsy. Ann. Surg. 1983;197:555-9.

11. Adair FE, et al. Long-term follow-up of breast cancer patients:The 30-year report. Cancer 1974;33:1145.

12. Yorkshire Breast cancer group. Symptoms and signs of operable breast cancer (1976-1981). Br. J. surg 1983;70:350.

13. Tommy E, Cupples GW, Eklund, et.al. Halo sign requisited Radiology 1996 Apr 1;99(1): 105-8.

14. Warren SL. Roentgenologic study of breast. AJR 1930;4:113. 
Mammographic evaluation of palpable breast masses with pathological correlation

15. Baker LH. Breast cancer detection demonstration project: five-year summary report. 1982; 32-194.

16. Mc. Clow MV, Williams AC. Mammographic examinations (4030):Ten year clinical experience in a community medical center. Ann. Sur. 1973;177:616.

17. Lesnick GJ. Detection of breast cancer in young women. JAMA 1977;237:967.

18. Strax P. Results of mass screening for breast cancer in 50,000 examinations. Cancer. 1976 Jan;37(1):30-5. 